the present state of speculation and hypothesis, and hopes for the coming of a great mind which will unify the whole.

Luftelektrizität. By Dr. Karl Kähler. Pp. I5I. (Berlin and Leipzig: G. J. Göschen'sche Verlagshandlung G.m.b.H., I913.) Price 90 pfennigs.

THIs is one of a long series of cheap, instructive books published by the firm of G. J. Göschen. The principal contents are the earth's potential gradient, forty-four pages; the electric conductivity of the atmosphere, thirty-five pages; electric currents in the air (including the ordinary fair-weather vertical current, electricity brought down by rain and snow, and lightning), twentynine pages; and the radio-active phenomena of the atmosphere, twenty-eight pages. Two other shorter sections deal respectively with the electric effects of sunshine and theories as to the source of atmospheric electricity. There are eighteen figures in the text, including some interesting Potsdam records of potential gradient during calm and disturbed weather. The author is a member of the staff of the Royal Meteorological-Magnetic Observatory at Potsdam, and is a recognised expert on the subject of which he treats. Considering its size, the book gives an excellent account, clear as well as concise, of the whole subject. German results loom somewhat more largely than they probably would in a text-book written in France or England, but there are a good many references to non-German writers, including Chauveau, Simpson, and C. T. R. Wilson.

Leçons sur les Hypothèses Cosmogoniques professées a la Sorbonne. By H. Poincaré. Edited by H. Vergne. Pp. lxx +294 . Second edition, with a Portrait and a Memoir on $\mathrm{H}$. Poincaré by E. Lebon. (Paris: A. Hermann et Fils, I9r3.) Price 12 francs.

THE first edition of this work was given an extended notice in the issue of NATURE for May 2, I9I2 (vol. Ixxxix., p. vi). The present issue has been enriched by a portrait of Prof. Poincaré, and by the inclusion of a biographical notice and critical estimate of the eminent savant's work by M. E. Lebon, who has in addition made a few necessary corrections in the text.

A Manual of Agricultural Chemistry. By $\mathrm{H}$. Ingle. Third edition. Pp. vii +397 . (London : Scott, Greenwood and Son, I913.) Price $7 s .6 d$. net.

THE first edition of Mr. Ingle's book-reviewed in the issue of Nature for July Io, 1902 (vol. 1xvi., p. 245)-dealt with the chemistry and physics of subjects relating exclusively to English agriculture. In the present edition, however, reference has been made to the chemistry of crops of tropical and sub-tropical countries, as well as to questions of stock-feeding in other lands. In addition, the book has been revised, and to bring it up to date some portions have been re-written.

\section{LETTERS TO THE EDITOR}

[The Editor does not hold himself responsible for opinions expressed by his correspondents. Neither can he undertake to return, or to correspond with the writers of, rejected manuscripts intended for this or any other part of NATURE. No notice is taken of anonymous communications.]

\section{Some Phenomena Connected with Reflected X-Rays}

The diagrams shown in Figs. I and 2 represent photographs obtained when $\mathrm{X}$-rays were refiected on rock-salt and quartz. The spots lying on the left of the vertical line are due to the rays which have passed directly through the crystal, while those on the right are produced by reflected rays. It is easy to see from Fig. 2 that there are five spots due to the impact of the reflected rays. The middle spot and the two on the outside are more intense than the two others. The optical axis of the quartz specimen lies in this case in the plane of incidence forming an angle of $x^{\prime}$ with the surface of the crystal.

An explanation of the different spots of reflection shown in Fig. 2 can be given with the help of Fig. 3,
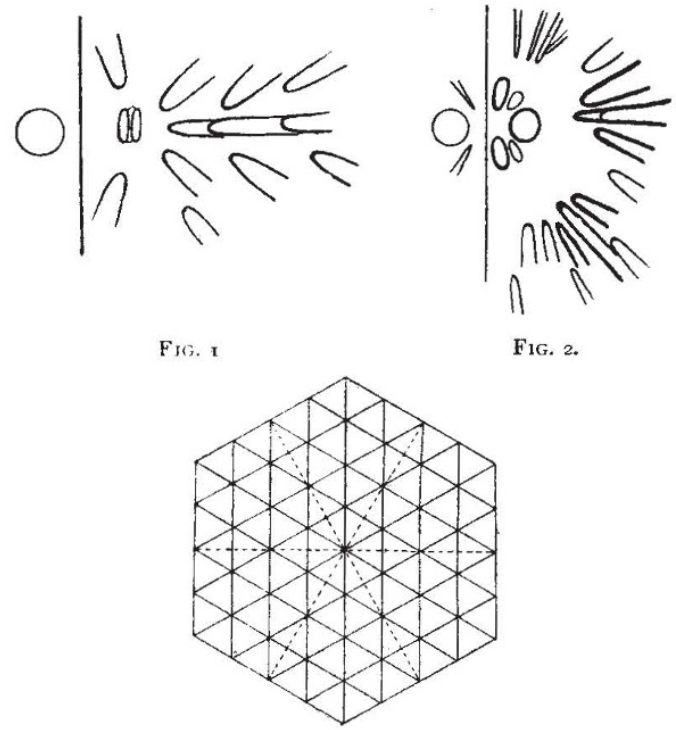

F1G. 2.

$$
\text { FIG } 3 \text {. }
$$

which is meant to show a cross-section of a hexagonal crystal cut at right angle to the optical axis. The points of intersection of the lines drawn in full may represent the positions of the molecules in the crystal. Considering this figure we can assume that the more intense rays are reflected by the layers which are parallel to the lines drawn in full, and the weaker ones by layers which are parallel to the dotted lines. It is obvious that in the first case the molecules lie closer together than in the second.

In addition, in Figs. $I$ and 2 there are seen a series of lines which seem to converge towards the points of impact of the reflected rays, and are distributed in a way which is very similar to a spectrum obtained with visible light by means of two crossed gratings. Provided that in our case the phenomenon is due to an effect similar to that of crossed gratings, the directly reflected rays must be regarded as spectra of the order zero. On account of the diffusion of the lines, however, it is not possible at present to deduce from this the wave-length of the $\mathrm{X}$-rays.

Physikalisch-technische Reichsanstalt, E. Hupka. Charlottenburg, April r2. 